\title{
A framework to identify constraints to post-extinction recovery of plant species-Application to the case of Bromus bromoideus
}

\author{
Sandrine Godefroid ${ }^{\mathrm{a}, \mathrm{b}, \mathrm{c}, *}$, Julien Piqueray ${ }^{\mathrm{d}}$, Louis-Marie Delescaille ${ }^{\mathrm{e}}$, Arnaud Monty ${ }^{\mathrm{f}}$, \\ Grégory Mahy ${ }^{\mathrm{f}}$ \\ ${ }^{a}$ Meise Botanic Garden, Nieuwelaan 38, 1860, Meise, Belgium \\ ${ }^{\mathrm{b}}$ Fédération Wallonie-Bruxelles, Service général de l'Enseignement supérieur et de la Recherche scientifique, rue A. Lavallée 1, 1080, Brussels, Belgium \\ ${ }^{\mathrm{c}}$ Université Libre de Bruxelles, Laboratory of Plant Ecology and Biogeochemistry, Avenue F. Roosevelt 50, 1050, Brussels, Belgium \\ ${ }^{\mathrm{d}}$ Natagriwal ASBL, site de Gembloux. Passage des Déportés 2, 5030, Gembloux, Belgium

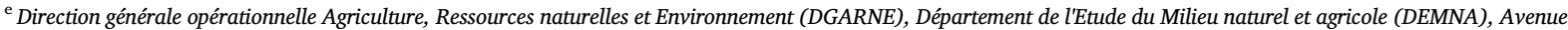 \\ Maréchal Juin 23, 5030, Gembloux, Belgium \\ ${ }^{\mathrm{f}}$ Université de Liège, Biodiversity and Landscape Unit, Gembloux Agro-Bio Tech, Passage des Déportés 2, 5030, Gembloux, Belgium
}

\section{A R T I C L E I N F O}

\section{Keywords:}

Arable plant

Species reintroduction

Conservation translocation

Post-extinction recovery

Decision tool

\begin{abstract}
A B S T R A C T
The reintroduction of plant species is a technique increasingly used to restore extirpated populations. Although most often used to improve the conservation status of endangered species, it can also be considered for species extinct in the wild. The process of resurrecting extinct plant species is however still in its infancy, and it entails additional challenges compared to the reintroduction of locally extinct populations. This study proposes a framework to analyse constraints to post-extinction recovery based on the case of Bromus bromoideus, a species endemic to southern Belgium and northern France, extinct in the wild since 1935. The plant still exists in ex situ collections, and seeds stored for decades at $5 \%$ moisture content and $-20{ }^{\circ} \mathrm{C}$ have shown a good viability. We initiated a feasibility study to assess the risks associated to a programme aiming at reviving this long-extinct species. Several constraints were identified. Biological constraints are related to the fuzzy taxonomy of the species, the unknown origin of the seeds and undocumented ex situ cultivation, and the likely low genetic diversity of the material available for reintroduction. Ecological constraints are linked to the habitat of the species. B. bromoideus has no known natural habitat and is only found in cultivated fields, which are by definition highly anthropized unprotected areas. This study shows the importance of undertaking a preliminary study that addresses all aspects of technical feasibility, scientific justification, biological and societal risks. Based on this exercise and inspired by international standards, we developed a decision tool to assist conservationists to resurrect a plant species in the best possible way.
\end{abstract}

\section{Introduction}

The reintroduction of plant species into the wild is a technique increasingly used today to restore populations of the most endangered species (e.g. Maschinski \& Haskins, 2012). This approach is particularly appropriate for species that do not have the ability to recover passively after restoration of their habitat, i.e. those with short-range dispersal capacity and transient seed bank in the soil. This includes a large number of plant species since only a very small proportion of them are able to disperse at more than a few tens of meters (Thomson, Moles, Auld, \& Kingsford, 2011). Also, for the European flora it turns out that only $17 \%$ of the 2,534 species analysed have a seed bank that persists for more than 5 years in the soil (Thompson, Bakker, \& Bekker, 1997.
The list of European threatened plants includes 1,917 taxa $15 \%$ of the European flora), $90 \%$ of which are single country endemics (Sharrock \& Jones, 2009). Potential candidates for reintroductions are therefore numerous, and nowadays the number of plant taxa involved in this type of program globally exceeds one thousand (e.g. Commander et al., 2018; Godefroid \& Vanderborght, 2011; Liu et al., 2015).

Although most often used to improve the conservation status of endangered species, reintroduction can also be considered for species extinct in the wild. The process of reintroducing extinct plant species is however still in its infancy, and it entails additional risks compared to the reintroduction of locally extinct populations (Abeli et al., 2020). Most significant risks include the loss or substantial change in the species' habitat, the low quality of ex situ material, or lack of knowledge

\footnotetext{
* Corresponding author at: Meise Botanic Garden, Nieuwelaan 38, 1860, Meise, Belgium.

E-mail address: sandrine.godefroid@botanicgardenmeise.be (S. Godefroid).
} 
relative to the ecological requirements of the target species. These risks are likely to increase as the time elapsed since the extinction of a species is high.

We here use the case of Bromus bromoideus, extinct in the wild since 1935 , to propose a framework for a risk analysis to post-extinction recovery. The present paper discusses its potential reintroduction by addressing the following questions: (1) is its reintroduction technically possible? and (2) is it a reasonable and legitimate conservation objective? After having outlined the decline of $B$. bromoideus until its extinction and its conservation in ex situ collections, we review options for its reintroduction by analysing the existing constraints and challenges (fuzzy taxonomy, questionable quality of ex situ material, likely low genetic diversity, no known natural habitat and possible mismatch between historical and current habitat). Based on that, we developed a nine-step decision tool in order to help conservationists make the most appropriate choices for reintroducing extinct species into the wild.

\section{A species soon extinct after its discovery}

B. bromoideus (Poaceae) is a $0.5-1 \mathrm{~m}$ high annual autogamous wind-pollinated species. It was discovered for the first time in 1821 in a spelt field in the eastern part of Belgium (Tournay, 1968). During the decades following its discovery, the species has been recorded in 49 locations in south east Belgium and one in the north of France, especially on poor dry calcareous soils. However, it has always had a restricted natural range, corresponding to the Meuse district, where it preferred clay-limestone or clay-schistose soils on hills and the top of these (Maréchal, 1937). Its extent of occurrence was $90 \mathrm{~km}$ in length and $10-15 \mathrm{~km}$ in width. B. bromoideus thrived in spelt fields until 1882 before starting to regress, even if, according to historical data, it was very common (Maréchal, 1937). It was observed in the wild for the last time in 1935 (de Cugnac, 1954). The gradual regression of the species can be explained by the reduction of spelt crops being progressively replaced by wheat. In addition, increasing livestock farming and dairy industry has led to the transformation of cultivated fields into grasslands (Maréchal, 1937). Use of commercial seeds and improved seed cleaning processes on the farm may also have contributed to the extinction of the species (Maréchal, 1937; Piqueray, Gilliaux, Gaillard, Mahy, \& Delescaille, 2018).

\section{Ex situ conservation}

Soon after its discovery, B. bromoideus generated a lot of enthusiasm among botanists, with the result that several botanical gardens wanted to have it in their collections. In the $19^{\text {th }}$ century, the species was grown in and distributed by 35 botanical gardens scattered all over Europe (de Cugnac, 1936). Over the years, due to a gradual decrease in interest in the plant, the number of institutions cultivating this species dropped to 5 in 1936. In addition to Copenhagen, Lund, Bucharest and Leningrad, the Botanical Garden (BG) of the University of Liège was the only Belgian ex situ infrastructure conserving the species after 1824. In the 1970s, a large part of the faculties moved to another site, and the university donated its cultivated plants to other botanical gardens. Many of these also closed and their collections were lost. However, in 1983 Meise BG received seeds from Liège BG. The history of this accession is not known, but it has presumably been repeatedly regenerated from wild seed collected several decades earlier. The accession donated by Liège BG was then cultivated between 1985 and 1990 and again between 2006 and 2012 at Meise BG. At present, the species is conserved in several ex situ infrastructures worldwide (Table 1). Genetic material is therefore safeguarded from total loss to science and society.

\section{Constraints to its reintroduction}

The species is strictly protected under Appendix 1 of the Convention on the Conservation of European Wildlife and Natural Habitats (Bern Convention). Seed availability led us to question its possible reintroduction into the wild. Through a risk and feasibility assessment, we identified following constraints to the recovery of this taxon.

\subsection{Fuzzy taxonomy}

Research conducted in the 20th century indicated undeniable genetic affinities between $B$. bromoideus, B. grossus and B. secalinus. According to Tournay (1968), B. bromoideus should be considered as a subspecies of B. grossus. Scholz (1970) considered B. bromoideus as a mutant of B. grossus. According to Smith (1973), however, B. bromoideus is so easily identified by its unique marginal lemma tooth that it must be clearly distinguished from the other species in the group. Ainouche and Bayer (1997) have undertaken a genetic study to unravel the relationships among closely related species of Bromus. Their study showed that the three species (B. bromoideus, B. grossus and B. secalinus) have the same ITS sequence, and these results are in line with Jauzein (1995) who considers B. bromoideus as a variant of B. grossus resulting from an accidental mutation. A more recent study using AFLP markers confirmed that $B$. bromoideus has evolved from within the $B$. grossus gene pool (Koch, Meyer, Engelhardt, \& Thiv, 2016).

Serious concerns regarding the taxonomic status and possible hybridization of some ex situ collections intended for reintroduction have already been raised previously with the extinct species Sophora toromiro that was endemic to Easter Island (Püschel, Espejo, Sanzana, \& Benítez, 2014). In the case of $B$. bromoideus, the ambiguity regarding its taxonomic status can however be somewhat alleviated by de Cugnac's work showing that experimental hybridization of $B$. bromoideus and B. grossus produces $B$. bromoideus var. villosa (with pubescent spikelets) but that the species remains very stable: its typical morphological characteristics as described by the first observers have been maintained for 130 years of uninterrupted cultivation at Liège BG.

\subsection{Questionable quality of ex situ material}

B. bromoideus is present in several ex situ collections around the world (Table 1). It turns out, however, that all available seeds were garden-collected from plants whose cultivation conditions have been poorly documented. Essential information is missing, e.g. the size of the ex situ population, the number of generations in cultivation, the proximity with closely related taxa. This situation can be delicate in the context of a possible reintroduction into the wild because it is well known that ex situ cultivated plants tend to adapt to the garden environment, for example by decreasing their stress tolerance or by losing seed dormancy (Ensslin, Sandner, \& Matthies, 2011; Ensslin, Tschöpe, Burkart, \& Joshi, 2015; Ensslin, Van de Vyver, Vanderborght, \& Godefroid, 2018). Fitness decline, trait changes and loss of advantageous stress responses could be maladaptive in the wild and they question the suitability of these garden populations as a source for reintroduction. This garden-raised material could also have been hybridized with closely related species, a possibility that was reported to us by some donor institutions.

Germination tests were carried out on several of these garden-grown accessions. Depending on the accession, we observed on average $72 \%$ germination (range: 6-100 \%) (Table 2). Knowing that the seeds can be conserved for several years without losing their viability (de Cugnac, 1954), we then examined the material available in herbarium vouchers. By focusing on the institution closest to the natural range of the species, we found 125 vouchers of $B$. bromoideus stored in the herbarium of Meise BG. Fifty seven percent of them are of known wild origin. Consequently, our only link with wild-collected material now lies in herbarium specimens. A limited number of seeds were carefully collected from a few herbarium specimens sampled between 1861 and 1879, and their viability was tested under the same conditions as for the seeds stored in the seed bank. None of these herbarium seeds germinated. 


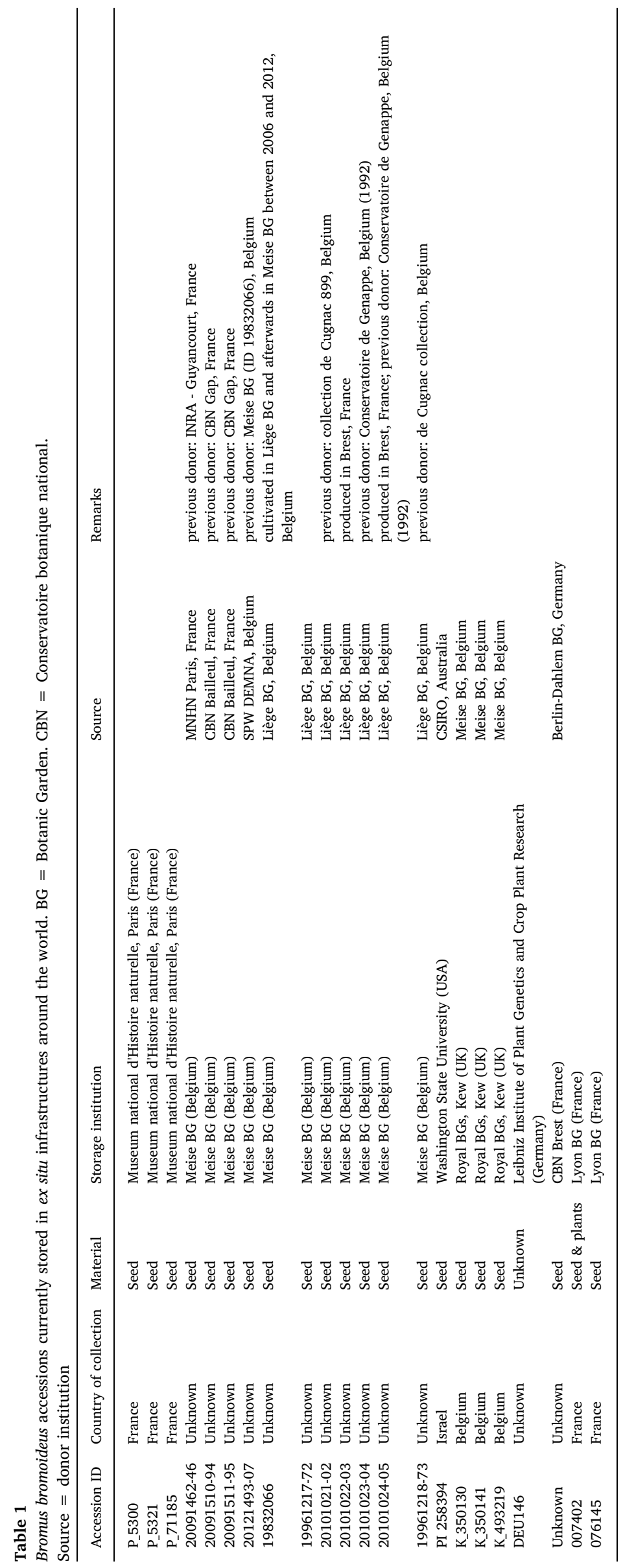


Table 2

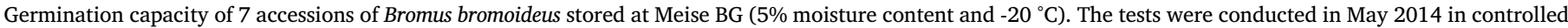

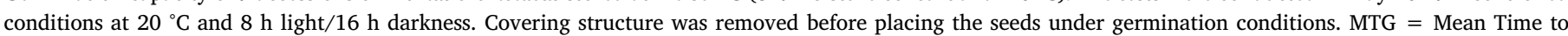
Germination (days).

\begin{tabular}{|c|c|c|c|c|c|c|c|c|c|}
\hline Accession ID & Tested seeds & Germinated seeds & Empty seeds & Mouldy seeds & Fresh seeds & Infested seeds & Abnormal seeds & MTG & Germination \% \\
\hline 19832066 & 15 & 15 & 0 & 0 & 0 & 0 & 0 & 3 & 100 \\
\hline 1996121772 & 16 & 1 & 0 & 15 & 0 & 0 & 0 & 9 & 6 \\
\hline 1996121873 & 17 & 12 & 0 & 5 & 0 & 0 & 0 & 7 & 71 \\
\hline 2009151195 & 6 & 6 & 0 & 0 & 0 & 0 & 0 & 7 & 100 \\
\hline 2010102203 & 15 & 13 & 0 & 2 & 0 & 0 & 0 & 3 & 87 \\
\hline 2010102304 & 12 & 8 & 0 & 4 & 0 & 0 & 0 & 4 & 67 \\
\hline 2010102405 & 18 & 18 & 0 & 0 & 0 & 0 & 0 & 3 & 100 \\
\hline
\end{tabular}

Although it has been shown previously that seeds of some species conserved in old herbarium vouchers can be able to germinate (Godefroid, Van de Vyver, Stoffelen, Robbrecht, \& Vanderborght, 2011), it must be recognized that this is a very rare exception because of the non-optimal conditions for preserving seeds in a herbarium.

To summarize the situation, seeds stored in ex situ collections can be divided into the following four categories in ascending order of conservation priority: (1) seeds from garden-cultivated plants; (2) loose seeds between the herbarium sheets not pertaining to a particular voucher; (3) seeds placed in envelopes attached to voucher specimens; and (4) seeds taken directly from voucher specimens. Seeds in category 1 have the least conservation value since they originate from seeds cultivated for at least 50 years. Categories 2 and 3 contain chance of human error. Seeds from category 4 originate from wild material verified by a taxonomist. Unfortunately, only category 1 seeds are able to germinate and therefore represent the only possible source of material for eventual recovery.

\subsection{Unknown (but likely low) genetic diversity}

The only viable material available has been grown in gardens for many years. We do not know the number of regeneration cycles, but it is supposed to be very high. According to de Cugnac (1936), no less than 35 botanical gardens throughout Europe cultivated and distributed B. bromoideus at some point during the 19th and 20th centuries. Of these, about ten have distributed the species without significant interruption for at least 20 years. Several of the accessions currently stored in different seed banks originate from the de Cugnac collection (Table 1), and we know that he has maintained the species in cultivation for crossing experiments with closely related species (Tournay, 1968). In addition, the species has been cultivated at the Liège BG for 130 years (de Cugnac, 1954) and this is where many samples distributed around the world come from (Maréchal, 1937). Most regeneration procedures are very inefficient (Lawrence, 2002) and previous studies have shown that much genetic variation is lost in ex situ collections compared to their wild source populations (Lauterbach, Burkart, \& Gemeinholzer, 2012; Rucińska \& Puchalski, 2011). Especially in annual arable plants, there is evidence that, in addition to their low levels of genetic diversity, ex situ populations also exhibit incomplete representation of alleles found in the wild (Brïtting, Hensen, \& Wesche, 2013). This phenomenon can be attributed to genetic drift, inbreeding depression and mutation accumulation (Havens, Guerrant, Maunder, \& Vitt, 2004), although it should be kept in mind that inbreeding depression is typically lower in annuals than in perennials (Husband \& Schemske, 1996; Morgan, 2001).

These genetic hazards are in fact the same as in small populations in the wild. In the case of $B$. bromoideus, ex situ populations have existed at low sizes for many generations. For annual species, conservationists advocate not to exceed 5-6 regeneration cycles in ex situ collections (Prasse, Kunzmann, \& Schröder, 2010; Schoen \& Brown, 2001; Walker, Hodder, Bullock, \& Pywell, 2004). It is therefore very likely that $B$. bromoideus seeds have a reduced genetic diversity, being repeatedly regenerated from wild seed collected over 85 years ago. Rare alleles are also most probably missing from the seed samples. In order to overcome the problem of a small founding population, multiple seed sources can be necessary to guarantee sufficient genetic diversity for a founding population (Vergeer, van den Berg, Roelofs, \& Ouborg, 2005). We have identified several accessions stored $e x$ situ, but they may represent very few seed provenances since most accessions result from exchange between institutions. This material duplication only heightens the doubt about the genetic diversity represented in these seed lots.

In practice there is little information available on whether most existing ex situ collections are genetically representative or not (GPPC, 2008). In the present case too, no molecular analysis has been done on the Bromus seeds. Even if self-pollinating species can efficiently purge strongly deleterious mutations causing inbreeding depression (e.g. Glémin, 2007), several publications have highlighted some deleterious effects of small populations (e.g. Barrett \& Kohn, 1991; Leimu, Mutikainen, Koricheva, \& Fischer, 2006; Reed, 2005). Combined with the growing number of empirical studies comparing the conservation value of ex situ populations with their wild source populations, all this information calls for caution with regard to the use of these seeds. Previously, there has already been another case where the reintroduction of an extinct plant species (Sophora toromiro) has been hindered because of uncertainties regarding the identity of some ex situ accessions and low levels of genetic diversity in the other remaining collections (Maunder, Culham, Bordeu, Allainguillaume, \& Wilkinson, 1999; Püschel et al., 2014).

\subsection{No known natural habitat}

Arable plants are an integral part of the history of agriculture in Europe. Some of them, like Bromus species of the grossus-secalinus-bromoideus complex, have been unintentionally selected because of their mimicry with cereals and have no natural habitat outside of crops (e.g. Koch et al., 2016). The most likely wild relatives are B. commutatus and/or B. racemosus, which occur in less artificial habitats such as fallow land for the former and wet meadows for the latter (Koch et al., 2016). B. bromoideus has however always been observed in spelt fields (Triticum spelta) on stony and calcareous soils (Lambinon \& Verloove, 2012; Tournay, 1968). This association is favored by a certain concordance between the vegetative requirements of $B$. bromoideus and the conditions offered by the cultivation of spelt (de Cugnac, 1954). B. bromoideus can be easily cultivated alone, as is done in botanic gardens, provided that it is itself treated as an over-wintering winter cereal, which also corresponds to the life cycle of spelt. In spelt crops, it was most often found in the seed line, suggesting that it was sown with spelt at the same time (Delescaille, Piqueray, \& Godefroid, 2011). Except for one case, $B$. bromoideus has never been observed in wheat or rye fields (Maréchal, 1937). These have naked grains, i.e. which are easily separated from the bales by threshing, while spelt has hulled grains, whose ears disarticulate by threshing, the grains remaining in the thick balls. As a result, spelt diaspores are much larger than those of wheat or rye. Sorting operations easily remove large seeds of $B$. bromoideus from 
wheat, while similarity in size will allow it to remain among spelt (de Cugnac, 1954). B. bromoideus seeds remain attached to the panicle at harvest time (late July/early August), so the spikelets are harvested with spelt.

Since reduced cultivation of certain traditional crops is one of the reasons why arable plants have decreased, we examined the current availability of the habitat required by $B$. bromoideus. In the $19^{\text {th }}$ century, spelt was a widely cultivated cereal, with 50,399 ha in Belgium in 1870 (Maréchal, 1937). Thereafter, the area planted with spelt declined significantly. It turns out, however, that this cereal is now experiencing a significant revival of interest with 13,176 ha in the southern half of Belgium (SPW, 2019), which includes the historical range of $B$. bromoideus.

\subsection{Possible mismatch between historical and current habitat}

A necessary requirement for a successful reintroduction is the suitability of the available habitat (Lawrence \& Kaye, 2011). Before any reintroduction, we must ensure that the targeted species and habitat match in ecological terms. Increased variability, in temperature or precipitation may make reestablishment of a historical system challenging (Falk \& Millar, 2016). Drought events were less common in the 20th century compared to now. B. bromoideus plants that will be derived from the propagation of ex situ stored material might therefore be less resistant to the effects of recurrent droughts that are currently observed (Grime et al., 2000).

Germination tests carried out on B. bromoideus seeds taken from plants repeatedly propagated in botanical gardens revealed the very rapid emergence of seedlings (between 3 and 9 days, Table 2). This is particularly fast, knowing that a closely-related species, B. secalinus, normally takes 14-35 days to germinate (Royal Botanic Gardens Kew, 2019). Such rapid germination could have been induced by an unconscious selection by gardeners for fast-germinating seeds, so that over decades they gradually lose their dormancy (Ensslin et al., 2018). Before the massive use of herbicides, early germination at low temperatures could have provided a developmental benefit for winter-annual species, as competition for light and nutrients is low at this early stage. However, with modern agricultural techniques, early germination of arable species becomes a disadvantage, because they are now particularly exposed to herbicide application and mechanical weeding (Albrecht, Cambecèdes, Lang, \& Wagner, 2016). This raises some concerns about the suitability of the present-day environment considering the very likely evolution of the species' traits after several decades of $e x$ situ cultivation.

Agricultural intensification also induced a higher competition from the cereal towards the arable flora, owing to (1) increased use of fertilizers, (2) development of more competitive crop varieties, e.g. spelt yield has increased by $9 \%$ in the target area (SPW, 2009), and (3) a trend towards sowing crops more densely (Albrecht et al., 2016). We therefore wanted to examine whether spelt density could have an influence on the vegetative development of B. bromoideus. Greenhouse trials on two different types of substrates have shown that the degree of competition with spelt does not significantly influence the time required for germination, the number of leaves or shoot height (Fig. 1). This experiment has emphasized that the plant shows a good fitness in different soil conditions and levels of competition with the cereal. It means that, even if it is genetically depleted, material from ex situ collections produced plants with some adaptive capacity. Accordingly, restored populations of $B$. bromoideus might have a reduced risk of extinction in the face of future environmental changes.

Re-establishing suitable conditions at the field level, for example through organic farming or agri-environment measures, may not be sufficient to recover populations of many arable species (Lang, Prestele, Fischer, Kollmann, \& Albrecht, 2016; Lemoine, Sérusiaux, Mahy, \& Piqueray, 2018). We do not know the persistence time in the soil for $B$. bromoideus seeds, but the closely related species $B$. secalinus has a
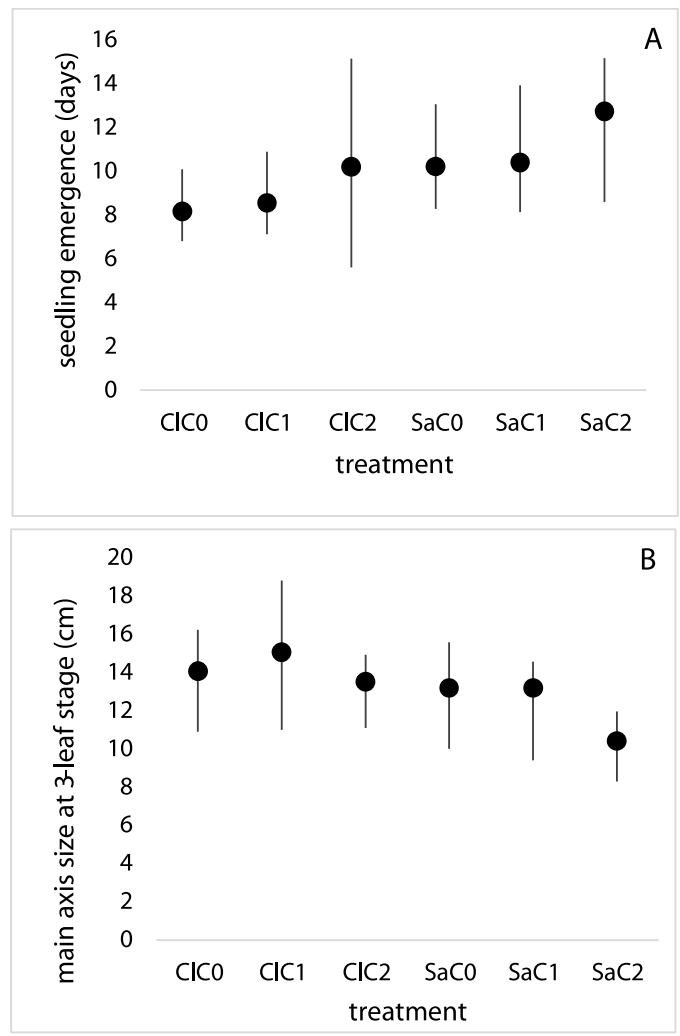

Fig. 1. Effect of soil type and competition with spelt (treatment) on two growth factors of $B$. bromoideus (A: seedling emergence; B: main axis size at 3-leaf stage) as analysed in a greenhouse experiment (average, max, min). Cl: clayloam soil; Sa: sandy soil; $\mathrm{C} 0$ : no competition (no spelt); $\mathrm{C} 1$ : intermediate competition (160 spelt seeds $/ \mathrm{m}^{2}$ ); C2: high competition (325 spelt seeds $/ \mathrm{m}^{2}$ ). No significant effect could be ascribed to either soil type or intensity of competition (two-way ANOVA's).

transient seed bank (Thompson et al., 1997). The reintroduction of these arable species is therefore doomed to failure at the field level due to crop rotation and needs to be considered at a multiple field level (Piqueray et al., 2018).

Another aspect that needs to be taken into account is that the current process of cleaning crop seeds is nothing like what existed a century ago. For the related species $B$. grossus, which behaves similarly to $B$. bromoideus, a $4 \mathrm{yr}$-monitoring of 8 experimental plots revealed that sowing uncleaned crop seed is an essential measure for the conservation of the arable flora, as populations of $B$. grossus were observed only after fields were seeded with uncleaned spelt (Piqueray et al., 2018).

\section{The importance of a feasibility and risk analysis}

At the European scale, as much as $\mathbf{5 8 2}$ arable species are listed as rare or threatened (Storkey, Meyer, Still, \& Leuschner, 2012). The reintroduction of rare arable plant species within agro-ecosystems by seed transfer has been proposed to improve their conservation status (Lang et al., 2016). Plant reintroductions can however be expensive, labourintensive, time-consuming, and they are far from guaranteeing success (Dalrymple, Banks, Stewart, \& Pullin, 2012; Godefroid et al., 2011; Gorbunov, Dzybov, Kuzmin, \& Smirnov, 2008). By conducting a feasibility assessment of the reintroduction of $B$. bromoideus, we have been able to identify several obstacles and risks to the recovery of this species in agro-ecosystems. Inspired by guiding principles recommended in international textbooks (Akeroyd \& Wyse Jackson, 1995; Commander et al., 2018; Falk, Constance, Millar, \& Olwell, 1996; IUCN/SSC, 2013, 2016; Maschinski \& Haskins, 2012; Maschinski \& Albrecht, 2017; Maslovat, 2009), this exercise helped develop a decision tool based on 9 
Table 3

Nine-step decision tree for considering the reintroduction of a plant species extinct in the wild.

1. Is the taxonomic status of the species clearly established?

Rationale: it must be ensured that the reintroduced taxon is a true species that is not likely to hybridize with other existing taxa

2. Is the material kept in ex situ collections of sufficient quality to be used as a seed source for reintroduction? Rationale: any reintroduction project requires detailed information about sources of propagated plant material

3. Are the biotic and abiotic needs of the species well known?

Rationale: a thorough knowledge of the requirements of the species is essential for successful reintroduction

4. Does the habitat of the species still exist today?

Rationale: optimal conservation of a species cannot be considered outside its original habitat

5 . Has the cause of the extinction of the target species been removed?

Rationale: the primary threats that led to extinction must be absent or well-regulated

6 . If the habitat has been modified, are there good prospects for restoration?

Rationale: the longer the time elapsed since the extinction of a species, the higher the probability that its habitat has been modified, requiring therefore some restoration in order to match the ecological requirements of the species

7. Do the sites targeted by the reintroduction benefit from a legal protection status ensuring their conservation in the long term?

Rationale: a secure long-term protection of the habitat is one of the prerequisites required for any reintroduction

8. Can adequate management aiming at the sustainability of reintroduced populations be guaranteed?

Rationale: long-term habitat management is most often required (unless reintroduction is located in a climax forest habitat) and should be secured

9. Does the reintroduction have a positive conservation benefit beyond the species level?

Rationale: to be scientifically, economically and socially tenable, any reintroduction attempt should have positive effects on the habitat considered, e.g. increasing ecosystem services, and/or reducing losses in other species
Yes $->$ go to 2

No $->$ consider an extensive taxonomic study, if necessary using molecular tools

Yes $->$ go to 3

No $->$ reject reintroduction unless risks and costs can be minimized

Yes $->$ go to 4

No $->$ conduct biological and ecological study

Yes $->$ go to 5

No $->$ reject reintroduction or try to restore the habitat

Yes $->$ go to 6

No $->$ first eliminate the origin of the problem

Yes $->$ go to 7

No $->$ reject reintroduction

Yes $->$ go to 8

No $->$ take steps to ensure this necessary protection

Yes $->$ go to 9

No $->$ reject reintroduction or conclude agreements with

reliable managers

Yes $->$ proceed with the reintroduction

No $->$ reduce the priority of reintroduction steps that are meant to assist conservationists to resurrect a plant species in the best possible way (Table 3 ). With this decision tree, we wanted to bring attention to steps required to help conservationists make informed decisions when planning the reintroduction of species extinct in the wild. In the case of B. bromoideus, although its taxonomic status is confused, hybridization experiments conducted over several decades with $B$. grossus have shown that $B$. bromoideus is a very stable species. In addition, both species have co-existed on the field for many decades while maintaining their typical morphological characteristics. Harming existing populations of $B$. grossus through gene flow can therefore be ruled out (step 1 of the decision tool; Table 3). Since no genetic study could be done on accessions stored in ex situ collections, we have no idea about the quality of this material. Despite this suboptimal situation, we believe that in this case it should not be a hindrance to an attempt to reintroduce the species. Indeed, B. bromoideus needs human intervention to persist since it is related to spelt crops where it must be sown every year or else it disappears. In the event that reintroduction would cause unforeseen side effects, nothing prevents us to stop sowing it and it will disappear again from the agricultural landscape. In addition, the recent experience gathered with $B$. grossus has shown that the costs associated with its reintroduction would be low thanks to the collaboration of a few farmers who are willing to adapt their farming practices (step 2). The main adaptation consists in keeping an uncleaned spelt seed stock that contains Bromus seeds. This is used to re-sow spelt fields year after year following the crop rotation. Sowing own seeds is still a widespread practice in mixed crop-livestock farms in southern Belgium. Also, the use of herbicides is prohibited in Bromus conservation fields. This is likely to induce yield decrease but may be compensated by an agro-environmental payment for the conservation of threatened arable plants (see Lemoine et al., 2018 for more details). For the most related species (B. grossus), an experiment launched recently revealed an average of 82 panicles of Bromus $/ \mathrm{m}^{2}$ in spelt fields (Piqueray et al., 2018). Financial compensation to support farmers in this project included only the field margin ( $12 \mathrm{~m}$ wide) and consisted of 1,250 EUR/ha of margin. In practice, however, most farmers sowed their entire fields with contaminated spelt (Piqueray et al., 2018).

For those ecological data that are not available for $B$. bromoideus, inferences can be made from $B$. grossus that is closely related and ecologically similar (Piqueray et al., 2018). We have also seen that experiments carried out in the laboratory and in the field have allowed us to refine our knowledge of the germination and growth requirements of $B$. bromoideus, making it possible to approach step 3 of the decision tree in a confident way. The only known habitat of B. bromoideus (although of anthropic origin, i.e. spelt fields) still exists today (step 4) and is even the subject of renewed interest from farmers (SPW, 2019), which at the same time significantly reduces the main cause of the species disappearance (step 5).

The behaviour of $B$. bromoideus on different soil types and degrees of competition with the cereal has been tested, thus validating the ability of the species to withstand the current habitat conditions (step 6). Within the geographical range of $B$. bromoideus, regional authorities designated the first nature reserve whose main objective is the restoration of extensive agricultural environments. This includes 5 ha arable field ( 3 more hectares will be available from 2020) dedicated to arable plant conservation, including Bromus conservation prescriptions. Since 2012, 15 farmers applied for the B. grossus conservation program and none of them has yet given up. This kind of initiative allows to develop durable actions to restore the arable flora, by ensuring longterm control of land use in legally-protected areas and avoiding being strongly dependent on the agricultural policy and on individual decisions which may change rapidly (step 7). In the absence of legal protection (nature reserve), reintroduction sites may however be maintained in the medium term through official agreements with farmers as part of agro-environment measures, which at the same time will also secure an adequate management of the target sites (step 8). As for $B$. grossus, the specifications of the agro-environment measures can be adapted to the objective (e.g. no fertilizer, no herbicides). In this respect, the European Common Agricultural Policy and the European Agricultural Fund for Rural Development have also a role to play.

The scientific evaluation of agri-environment measures used for $B$. grossus has shown that the agricultural practices necessary for its reintroduction have doubled the specific richness of the targeted fields (Piqueray et al., 2018). This significant increase in associated biodiversity shows that there was a real benefit beyond the species level, and there is every reason to believe that this will also be the case with $B$. bromoideus (step 9).

\section{Conclusions}

So far, only a very limited number of attempts to start a reintroduction program of extinct plant species have been made, and 
many of them have failed (Abeli et al., 2020). Yet, botanical gardens around the world offer considerable potential in this area, with more than 80,000 species cultivated, among which 15,000 are threatened with extinction (Hurka, Neuffer, \& Friesen, 2004). Further information is however clearly needed on the conservation value of these plant collections in botanic gardens (Sharrock \& Jones, 2009), and the case presented in this paper is a representative example. In view of the problems of plant adaptation to garden conditions, hybridization risk and loss of genetic diversity during each regeneration cycle, seed storage is the preferred method because it avoids these issues that can have critical consequences for the reintroduction of plants into the wild. However, seed banking freezes the evolutionary development of a species, which decreases its chances of adapting to environmental change (Kennedy, 2004), especially when the time elapsed between extinction and reintroduction is long. All these situations that can lead to poor suitability of the ex situ material probably explain why so little reintroductions of extinct plant species have been attempted and successful.

On the other hand, as problems arising from ex situ cultivation are likely to get worse over time, assessing the risks and opportunities of reintroduction programs should ideally be considered - and the program started where appropriate - as soon as possible, otherwise the relevance of continued cultivation might be questioned. In the particular case of B. bromoideus, the expression "better late than never" might typically apply.

While many plant species extinct in the wild could potentially be resurrected thanks to ex situ-stored material, the present contribution shows the importance of undertaking a preliminary study that addresses all aspects of technical feasibility, scientific justification, biological and societal risks and potential benefits for the ecosystem concerned. It is only in this way that conservationists will be able to make sound decisions, to the advantage of the ecosystems concerned and in accordance with international guidelines. In the present study, the level of risk could be balanced against the expected benefits. This exercise was facilitated by using a decision tree such as the one we proposed. In the case of $B$. bromoideus, despite the obstacles identified, we can conclude that the reintroduction of this species may be considered low risk in terms of the cost of failure or the probability of adverse ecological impacts. We also recommend experimental reintroduction trials. With thorough documentation and ongoing monitoring, it is an ideal precautionary approach to minimize risks.

\section{Declaration of Competing Interest}

The authors declare that they have no known competing financial interests or personal relationships that could have appeared to influence the work reported in this paper.

\section{Acknowledgements}

We are grateful to Dave Aplin for his work on herbarium vouchers and seed collections, and Ann Van de Vyver for the germination tests. We thank the students Kathy Danhieux, Benoit Delpeuch, Abigail de Martynoff, Maïté Deplechin, Florence Hecq and Christine Poelaert, who contributed to data collection. Suzanne Sharrock (BGCI) and Koen Es (Meise BG) contributed to searching for accessions currently stored $e x$ situ worldwide. We also thank the reviewers for their constructive comments on an earlier version of this paper.

\section{Appendix A. Supplementary data}

Supplementary material related to this article can be found, in the online version, at doi:https://doi.org/10.1016/j.jnc.2020.125802.

\section{References}

Abeli, T., Dalrymple, S., Godefroid, S., Mondoni, A., Müller, J., Rossi, G., et al. (2020). Ex situ plant collections and their potential for restoration of genetic diversity back to the wild. Conservation Biology. https://doi.org/10.1111/cobi.13391 Early view.

Ainouche, M. L., \& Bayer, R. J. (1997). On the origins of the tetraploid Bromus species (section Bromus, Poaceae): Insights from internal transcribed spacer sequences of nuclear ribosomal DNA. Genome, 40, 730-743.

Akeroyd, J., \& Wyse Jackson, P. (1995). A handbook for botanic gardens on the reintroduction of plants to the wild. Richmond: BGCI.

Albrecht, H., Cambecèdes, J., Lang, M., \& Wagner, M. (2016). Management options for the conservation of rare arable plants in Europe. Botany Letters, 8107, 1-27.

Barrett, S. C. H., \& Kohn, J. R. (1991). Genetic and evolutionary consequences of small population size in plants: Implications for conservation. In D. A. Falk, \& K. E. Holsinger (Eds.). Genetics and conservation of rare plants (pp. 3-30). New York: Oxford University Press.

Brütting, C., Hensen, I., \& Wesche, K. (2013). Ex situ cultivation affects genetic structure and diversity in arable plants. Plant Biology, 15, 505-513.

Commander, L. E., Coates, D., Broadhurst, L., Offord, C. A., Makinson, R. O., \& Matthes, M. (2018). Guidelines for the translocation of threatened plants in Australia (3rd ed.). Canberra: Australian Network for Plant Conservation.

Dalrymple, S. E., Banks, E., Stewart, G. B., \& Pullin, A. S. (2012). A meta-analysis of threatened plant reintroductions from across the globe. In J. Maschinski, \& K. E. Haskins (Eds.). Plant reintroduction in a changing climate - Promises and perils (pp. 3152). Washington: Island Press

de Cugnac, A. (1936). Les Jardins botaniques et la conservation des espèces rares. A propos de Bromus arduennensis Dmrt., Liste de 35 jardins où $B$. arduennensis (= f. arduennensis) a été cultivé. Bulletin du Muséum national d'histoire naturelle, 2, 286-289.

de Cugnac, A. (1954). Le brome des Ardennes - l'étonnante carrière d'une espèce rare des confins ardennais. Bulletin de la Société des Naturalistes luxembourgeois, 58, 38-75.

Delescaille, L. M., Piqueray, J., \& Godefroid, S. (2011). Le statut du brome épais (Bromus grossus) en Région Wallonne. Adoxa, 69(70), 1-14.

Ensslin, A., Sandner, T. M., \& Matthies, D. (2011). Consequences of ex situ cultivation of plants: Genetic diversity, fitness and adaptation of the monocarpic Cynoglossum officinale L. in botanic gardens. Biological Conservation, 144, 272-278.

Ensslin, A., Tschöpe, O., Burkart, M., \& Joshi, J. (2015). Fitness decline and adaptation to novel environments in ex situ plant collections: Current knowledge and future perspectives. Biological Conservation, 192(394), 401.

Ensslin, A., Van de Vyver, A., Vanderborght, T., \& Godefroid, S. (2018). Ex situ cultivation entails high risk of seed dormancy loss on short-lived wild plant species. The Journal of Applied Ecology, 55, 1145-1154.

Falk, D. A., \& Millar, C. (2016). The influence of climate variability and change on the science and practice of restoration ecology. In M. A. Palmer, J. B. Zedler, \& D. A. Falk (Eds.). Foundations of restoration ecology (pp. 484-513). Washington: Island Press.

Falk, D. A., Constance, I., Millar, C. I., \& Olwell, M. (1996). Guidelines for developing a rare plant reintroduction plan. In D. A. Falk, C. I. Millar, \& M. Olwell (Eds.). Restoring diversity: Strategies for reintroduction of endangered plants (pp. 453-490). Washington: Island Press.

Glémin, S. (2007). Mating systems and the efficacy of selection at the molecular level. Genetics, 177, 905-916.

Godefroid, S., Van de Vyver, A., Stoffelen, P., Robbrecht, E., Vanderborght, T., et al. (2011). Testing the viability of seeds from old herbarium specimens for conservation purposes. Taxon, 60, 565-569.

Godefroid, S., \& Vanderborght, T. (2011). Plant reintroductions: The need for a global database. Biodiversity and Conservation, 20, 3683-3688.

Godefroid, S., Piazza, C., Rossi, G., Buord, S., Stevens, A. D., Aguraiuja, R., et al. (2011) How successful are plant species reintroductions? Biological Conservation, 144 $672-682$.

Gorbunov, Y. N., Dzybov, D. S., Kuzmin, Z. E., \& Smirnov, I. A. (2008). Methodological recommendations for botanic gardens on the reintroduction of rare and threatened plants. Tula: Grif \& Co.

GPPC (2008). Plant conservation report. A review of progress in implementing the global strategy for plant conservation (GSPC)Dublin: Global Partnership for Plant Conservation.

Grime, J. P., Brown, V. K., Thompson, K., Masters, G. J., Hiller, S. H., Clarke, I. P., et al. (2000). The response of two contrasting limestone grasslands to simulated climate change. Science, 289, 762-765.

Havens, K., Guerrant, E. O., Maunder, M., \& Vitt, P. (2004). Guidelines for ex situ conservation collection management. Minimizing risks. In E. O. Guerrant, K. Havens, \& M. Maunder (Eds.). Ex situ plant conservation: Supporting species survival in the wild (pp. 454-473). Washington: Island Press.

Hurka, H., Neuffer, B., \& Friesen, N. (2004). Plant genetic resources in Botanical Gardens Acta Horticulturae, 651, 35-44.

Husband, B. C., \& Schemske, D. W. (1996). Evolution of the magnitude and timing of inbreeding depression in plants. Evolution, 50, 54-70.

IUCN/SSC (2013). Guidelines for reintroductions and other conservation translocations. Version 1.0. Gland: IUCN/SSC.

IUCN/SSC (2016). IUCN SSC guiding principles on creating proxies of extinct species for conservation benefit. Version 1.0. Gland: IUCN Species Survival Commission.

Jauzein, P. (1995). Flore des champs cultivés. Paris: INRA.

Kennedy, K. L. (2004). The role of federal guidance and state and federal partnership in ex situ plant conservation in the United States. In E. O. Guerrant, K. Havens, \& M. Maunder (Eds.). Ex situ plant conservation: Supporting species survival in the wild (pp. 67-83). Washington: Island Press.

Koch, M. A., Meyer, N., Engelhardt, M., \& Thiv, M. (2016). Morphological and genetic 
variation of highly endangered Bromus species and the status of these Neolithic weeds in Central Europe. Plant Systematics and Evolution, 302, 515-525.

Lambinon, J., \& Verloove, F. (2012). Nouvelle Flore de la Belgique, du Grand-Duché de Luxembourg, du Nord de la France et des Régions voisines (Ptéridophytes et Spermatophytes) (6th ed.). Meise: Jardin botanique national de Belgique.

Lang, M., Prestele, J., Fischer, C., Kollmann, J., \& Albrecht, H. (2016). Reintroduction of rare arable plants by seed transfer. What are the optimal sowing rates? Ecology and Evolution, 6, 5506-5516.

Lauterbach, D., Burkart, M., \& Gemeinholzer, B. (2012). Rapid genetic differentiation between ex situ and their in situ source populations: an example of the endangered Silene otites (Caryophyllaceae). Botanical Journal of the Linnean Society, 168, 64-75.

Lawrence, M. J. (2002). A comprehensive collection and regeneration strategy for ex situ conservation. Genetic Resources and Crop Evolution, 49, 199-209.

Lawrence, B. A., \& Kaye, T. N. (2011). Reintroduction of Castilleja levisecta: Effects of ecological similarity, source population genetics, and habitat quality. Restoration Ecology, 19, 166-176.

Leimu, R., Mutikainen, P., Koricheva, J., \& Fischer, M. (2006). How general are positive relationships between plant population size, fitness and genetic variation? The Journal of Ecology, 94, 942-952.

Lemoine, C., Sérusiaux, E., Mahy, G., \& Piqueray, J. (2018). Agro-environmental scheme for segetal plant conservation in Wallonia (Belgium): An assessment in conventional and organic fields. Biotechnology, Agronomy, Society and Environment, 22, 35-44.

Liu, H., Ren, H., Liu, Q., Wen, X. Y., Maunder, M., \& Gao, J. Y. (2015). Translocation of threatened plants as a conservation measure in China. Conservation Biology, 29, $1537-1551$.

Maréchal, A. (1937). Note sur Bromus arduennensis Dmrt. et sur le rôle des jardins botaniques dans la conservation des espèces rares. Bulletin de la Société royale de Botanique de Belgique, 70, 51-58.

Maschinski, J., \& Albrecht, M. A. (2017). Center for plant conservation's best practice guidelines for the reintroduction of rare plants. Plant Diversity, 39, 390-395.

Maschinski, J., \& Haskins, K. E. (2012). Plant reintroduction in a changing climate. Promises and perils. Washington: Island Press.

Maslovat, C. (2009). Guidelines for translocation of plant species at risk in British Columbia. Victoria: Ministry of Environment.

Maunder, M., Culham, A., Bordeu, A., Allainguillaume, J., \& Wilkinson, M. (1999) Genetic diversity and pedigree for Sophora toromiro (Leguminosae): A tree extinct in the wild. Molecular Ecology, 8, 725-738.

Morgan, M. T. (2001). Consequences of life history for inbreeding depression and mating system evolution in plants. Proceedings of the Royal Society of London Series BBiological Sciences, 268, 1817-1824.

Piqueray, J., Gilliaux, V., Gaillard, T., Mahy, G., \& Delescaille, L. M. (2018). Uncleaned crop seed sowing as a tool to conserve Bromus grossus and restore species-rich arabledependent plant communities. Conservation Evidence, 15, 26.32.

Prasse, R., Kunzmann, D., \& Schröder, R. (2010). Entwicklung und praktische Umsetzung naturschutzfachlicher Mindestanforderungen an einen Herkunftsnachweis für gebietseigenes Wildpflanzensaatgut krautiger Pflanzen Abschlussbericht. Hannover: Institut für Umweltplanung.

Püschel, T. A., Espejo, J., Sanzana, M. J., \& Benítez, H. A. (2014). Analysing the floral elements of the lost tree of Easter Island: A morphometric comparison between the remaining ex-situ lines of the endemic extinct species Sophora toromiro. PloS One, 9(12), e115548. https://doi.org/10.1371/journal.pone.0115548.

Reed, D. H. (2005). Relationship between population size and fitness. Conservation Biology, 19, 563-568.

Royal Botanic Gardens Kew (2019). Seed information database (SID). Version 7.1. http:// data.kew.org/sid/.

Rucińska, A., \& Puchalski, J. (2011). Comparative molecular studies on the genetic diversity of an ex situ garden collection and its source population of the critically endangered polish endemic plant Cochlearia polonica E. Fröhlich. Biodiversity and Conservation, 20, 401-413.

Schoen, D. J., \& Brown, A. H. D. (2001). The conservation of wild plant species in seed banks. BioScience, 51, 960-966.

Scholz, H. (1970). Zur Systematik der Gatung Bromus L. subg. Bromus (Graminae). Willdenowia, 6, 139-160.

Sharrock, S., \& Jones, M. (2009). Conserving Europe's threatened plants: Progress towards target 8 of the global strategy for plant conservation. Richmond: Botanic Gardens Conservation International.

Smith, P. M. (1973). Observations on some critical Brome grasses. Watsonia, 9, 319-332. SPW (2009). Evolution de l'économie agricole et horticole de la Région wallonne 2008-2009. Jambes: Service Public de Wallonie, Département de l'Etude du Milieu naturel et agricole.

SPW (2019). Evolution de l'économie agricole et horticole de la Wallonie. Jambes: Service Public de Wallonie, Département de l'Etude du Milieu naturel et agricole.

Storkey, J., Meyer, S., Still, K. S., \& Leuschner, C. (2012). The impact of agricultural intensification and land-use change on the European arable flora. Proceedings of the Royal Society B Biological Sciences, 279, 1421-1429.

Thompson, K., Bakker, J., \& Bekker, R. (1997). The soil seed bank of North West Europe: Methodology, density and longevity. Cambridge: Cambridge University Press.

Thomson, F. J., Moles, A. T., Auld, T. D., \& Kingsford, R. T. (2011). Seed dispersal distance is more strongly correlated with plant height than with seed mass. The Journal of Ecology, 99, 1299-1307.

Tournay, R. (1968). Le Brome des Ardennes, "Bromus arduennensis" et ses proches, $B$. secalinus et B. grossus. Bulletin du Jardin botanique national de Belgique, 38, 295-379.

Vergeer, P., van den Berg, L. J. L., Roelofs, J. G. M., \& Ouborg, N. J. (2005). Single-family versus multi-family introductions. Plant Biology, 7, 509-515.

Walker, K. J., Hodder, K. H., Bullock, J. B., \& Pywell, R. F. (2004). A review of the potential effects of seed sowing for habitat re-creation on the conservation of intraspecific biodiversity. Defra Contract BD1447. Monks Wood: Centre for Ecology and Hydrology. 